\title{
Cl-Sn (Chlorine-Tin)
}

\section{H. Okamoto}

[Massalski2] showed a partial $\mathrm{Sn}-\mathrm{Cl}$ phase diagram copied from [1977The] for the composition range between $\mathrm{Sn}$ and $\mathrm{SnCl}_{2}$. Prior to [1977The], [1972Chi] reported a partial phase diagram between $\mathrm{SnCl}_{2}$ and $\mathrm{SnCl}_{4}$. Afterward, [1978Pop] reported a complete $\mathrm{Sn}-\mathrm{Cl}$ phase diagram. No significant conflicts are seen among these three reports.

The $\mathrm{Sn}-\mathrm{Cl}$ phase diagram shown in Fig. 1 was drawn in this work based on [1978Pop]. In order to eliminate unlikely features in [1978Pop], modification has been made by taking into account [1972Chi] and [1977The].

$\mathrm{Sn}-\mathrm{Cl}$ crystal structure data are given in Table 1.

\section{References}

1972Chi: N.D. Chikanov, The $\mathrm{Sn}^{2+}, \mathrm{Sn}^{4+}, \mathrm{Sn}^{3+}, \mathrm{Sn}^{5+} \| \mathrm{Cl}$ System, Russ. J. Inorg. Chem., 1972, 17(1), p 147

1977The: F. Thevet and C. Dagron, Partial Constitution of Binary Tin-Chlorine, Contribution to the Study of Iodide and Chloride Stannous Systems; Evidence of Presence of Two Iodochlorides, Bull Soc. Chim. Fr., Part 1, 1977, 11-12, p 1078-1080, in French

1978Pop: A.P. Popov, T.I. Kurdina, and K.T. Panina, Fusion Diagram of the Sn-Cl System, Russ. J. Inorg. Chem., 1978, 12, p 463-465

Table 1 Sn-Cl crystal structure data

\begin{tabular}{|c|c|c|c|c|c|}
\hline Phase & Composition, at. $\% \mathrm{Cl}$ & Pearson symbol & Space group & Strukturbericht designation & Prototype \\
\hline$(\beta S n)$ & 0 & $t I 4$ & $I 4_{1} /$ amd & $A 5$ & $\beta \mathrm{Sn}$ \\
\hline$(\alpha \mathrm{Sn})$ & 0 & $c F 8$ & $F d \overline{3} m$ & $A 4$ & $\mathrm{C}$ (diamond) \\
\hline $\mathrm{SnCl}_{2}$ & 66.7 & $o P 12$ & Pnam & $\ldots$ & $\cdots$ \\
\hline $\mathrm{SnCl}_{4}$ & 80 & $m P 20$ & $P 2_{1} / c$ & $\ldots$ & $\ldots$ \\
\hline$(\mathrm{Cl})$ & 100 & $o C 8$ & Cmca & $A 14$ & I \\
\hline
\end{tabular}

Weight Percent Chlorine

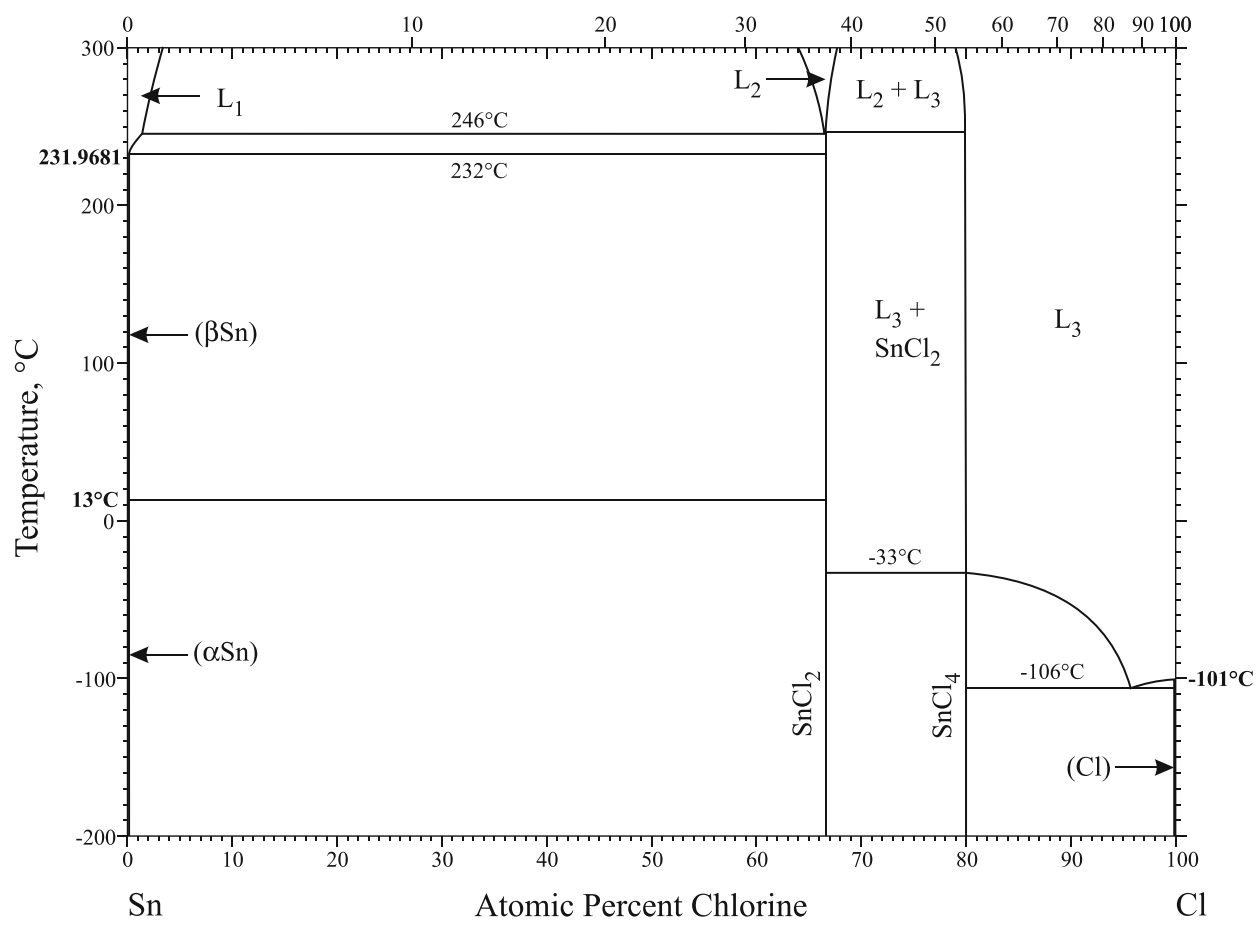

Fig. $1 \mathrm{Sn}-\mathrm{Cl}$ phase diagram 